\title{
Gender and Supportive Moves of Criticism: Evidence from Iraqi-Arabic and Malay Speech Communities
}

\section{Asst. Prof. Shurooq Abboodi Ali (Ph.D.)}

E-mail: shurooq_eng@yahoo.com

University of Baghdad, College of Arts, Department of English Language, Baghdad, Iraq

(Received on 16/12/2019 - Accepted on 21/1/2020 - Published on 1/6/2020)

DOI: https://doi.org/10.36586/jcl.2.2020.0.42.0027

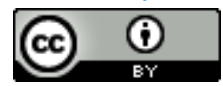

This work is licensed under a Creative Commons Attribution 4.0 International Licens

Abstract

This study aims to reveal the similarities and differences between Iraqi and Malay university learners and their genders in producing the supportive moves of criticism. To this end, 30 Iraqi and 30 Malay university learners have participated in this study. A Discourse Completion Test (DCT) and a Focus Group Interview (FGI) are conducted to elicit responses from the participants. Nguyen's (2005) classification of criticism supportive moves is adapted to code the data. The data are analysed qualitatively and quantitatively. Overall, the findings unveil that both groups use similar categories of supportive moves, but Iraqis produce more of these devices than Malays in their criticisms. Although both females and males of both groups use identical devices, they differ in their preference for producing particular types. Iraqi and Malay females prefer to produce more supportive moves than Iraqi and Malay males in their criticisms. Finally, the study provides some pedagogical implications for teachers of English as a second 
and foreign language.

Keywords: Criticism, supportive moves, gender, Iraqis, Malays

\section{Introduction}

Cross-cultural pragmatics investigates two different cultures in terms of certain features of language use such as speech acts, language performance, and forms of behaviour (Kecskes, 2017, p. 400). Language users can produce speech acts properly via controlling the use of the linguistic tools that are related to the values of appropriateness in a certain context (Roever, 2006). The speech act of criticism is one of the face threatening acts that has been conducted on few studies to date (Al Kayed and Al-Ghoweri, 2019; Farnia and Abdul Sattar, 2015; Abdullah, 2013; Darweesh, 2011; Nguyen, 2008, 2005). These studies have not studied the criticism supportive moves by two ESL (English as a second language) learners and by their genders. Thus, it is necessary to know the pragmatic competence in using mitigators by second language learners who have two different cultural backgrounds: Iraqi and Malay. Accordingly, the present study fills a gap in cross-cultural pragmatics by investigating the similarities and differences between Iraqi and Malay ESL learners in the production of criticism supportive moves. It also reveals the (dis)similarities between the females and males of each group in using the supportive moves of criticism. Therefore, this study seeks answers to the following research questions:

1. What types of supportive moves do Iraqi and Malay university learners tend to use in their criticisms?

2. What are the similarities and differences between Iraqi and Malay university learners in the use of criticisms supportive moves? 
3. What types of supportive moves do Iraqi and Malay females and males prefer to use in their criticisms?

\subsection{Literature Review/ Theoretical Background}

\subsubsection{Speech Act with Special Reference to Criticism}

The speech act theory has attracted the attention of scholars in a great deal of studies to date. Austin (1962) originated that theory by stating that language users produce utterances to accomplish actions in their life. It is then developed by Searle (1979) into a number of categories alongside identifying direct and indirect types of speech acts. The speech act of criticism is one of the face damaging acts because it threatens the positive face of the hearer (Brown and Levinson, 1987). It is commonly used in exchanges between users of language and it is as significant as other speech acts such as request, apology, complaint...etc. (Min, 2008). In addition, it is an illocutionary act which indicates an undesirable evaluation on the hearer's behaviour for which s/he might be responsible for. It is used to improve the hearer's future performance for the better or to interact with the speaker's dissatisfaction without indicating that that hearer's performance has negative consequences for the speaker (Nguyen, 2005, p. 7; Wierzbicka, 1987, p. 36). The criticism is used in diverse cultures with regard to the pragmatic competence of its users and the social beliefs of each culture (Nguyen, 2005, p. 112).

Based on Leech (1983) and Thomas (1983), Nguyen (2005, pp. 15, 112-114) states that the criticism could be performed via the pragmalinguistic and sociopragmatic competence of its users. The former focuses on the linguistic strategies and mitigators while the latter is 
concerned with the use of these linguistic aspects properly with reference to the values of second language. Thus, the speech act of criticism consists of semantic formulas which are varied in content and occurrence and are affected by the social variables such as gender, status, distance...etc.

In pragmatics, modifiers are used to mitigate the impact of the speech act when it is face-damaging such as request, complaint, chastisement...etc. Internal modifiers are used within the head act whereas the external modifiers occur before and/or after it. The latter do not influence the head act as far as they affect the context in which the act takes place. Different devices of external modifiers can be used to mitigate the illocutionary force of the act (Blum-Kulka et al., 1989). The mitigators derive their politeness degree when used in a specific situation because they are context-specific (Bella, 2011). Their main function is to mitigate the illocutionary force of the speech act (Caffi, 1999; Fraser, 1990). With reference to criticism, internal mitigators are syntactic and lexical/phrasal devices occurring within the head act while the external mitigators or supportive moves (such as 'steers', 'sweeteners', 'disarmers', and 'grounders') occur before and/or after it. These mitigators are used to ameliorate the face damaging of criticism (Nguyen, 2005, p 115-116). However, this study focuses on the supportive moves of criticism to show to what extent Iraqi and Malay university learners and their genders look like or differ in their production of these mitigators.

\subsubsection{Selected Studies}

Several studies have studied the speech act of criticism produced by ESL or EFL (English as a foreign language) learners. For instance, Al Kayed and Al-Ghoweri (2019) investigated the criticism strategies produced by 120 Jordanian students who are undergraduates in Jordan. The data are collected 
using Discourse Completion Task (DCT) which includes 10 scenarios. The data are coded based on Nguyen's (2005) model of criticism strategies. The findings uncover that the participants use more indirect strategies than direct ones in performing criticism.

Farnia and Abdul Sattar (2015) carried out research to study the response to criticism by 100 Persians in their Persian culture. A discourse evaluation test and a structured interview are conducted to collect the data in the study. The data are analysed in terms of Nguyen's (2005) classification of criticism strategies and external mitigators. The findings show that Persians resort to direct strategies more than indirect strategies and they underuse their responses of criticism by external mitigators.

Abdullah (2013) also examined 'criticizing' and 'responding to criticism' by Egyptian learners of English. The research also studied the impact of gender and the learners' proficiency level on the frequency of pragmatic transfer. An 'open-ended questionnaire' is applied to 40 native speakers of English and 40 Egyptian learners of English. The findings uncover some diversities and similarities between the two groups in the use of strategies and mitigators. They also unveil that gender and the level of proficiency affect the occurrence of pragmatic transfer.

Darweesh (2011) studied the speech act of criticism written in the Arabic journals to reveal the linguistic strategies produced by Arabs to deal with the effect of criticism properly. The findings show that Arabs use more indirect strategies than the direct ones in their criticisms. They also reveal that Arabs tend to use more off-record strategy in their criticisms in the Arabic journals. 
Nguyen (2008) carried out research to reveal the way ESL learners produce the criticism in their everyday situations. The participants consist of 5 New Zealand English speakers and 5 intermediate learners whose first language is mixed. Eight situations in a role-play are designed to collect the data. The findings unveil that the learners depend on direct criticism while the native speakers regularly produce all the strategies. Although the learners use similar strategies of the native speakers, they differ in their preference for the semantic formulas and modifiers.

Nguyen (2005) conducted developmental research to examine 'criticism' and 'response to criticism' by 36 Vietnamese learners and 24 native speakers of Vietnamese and Australian English. A written DCT, a role play, and retrospective interviews are conducted to collect the data. The findings uncover that the Vietnamese learners' utterances are different from the utterances of native speakers of Australian English. That is related to certain factors such as the lack of second language pragmatic competence, learning experience, transfer from the first language, and processing difficulty. Moreover, it is discussed that proficiency has a little effect on the production of the learners and the pragmatic transfer influences that production.

To conclude, the previous studies reveal that the speech act of criticism is still under-study and needs more investigation into the non-western societies. This study is of value because no similar research investigated the supportive moves of criticism as they are used by Iraqi and Malay ESL learners in their cultures. Besides, the gender tendency of using these mitigators has not been studied so far.

\section{Methodology}




\subsection{Participants}

The participants are selected randomly in this study. They are asked to provide personal information in a background questionnaire (refer to Appendix A). Thus, 30 Iraqi and 30 Malay university learners have participated in this study. They are MA students in diverse scientific fields at Universiti Sains Malaysia, Malaysia. Malaysian Malays are chosen for keeping homogeneity of these learners. Both groups consist of 15 males and 15 females whose ages range from 25 to 35 . The tasks are applied to each group separately and the researcher has explained all the information about the tasks. A consent form is provided by each participant and an hour is devoted for each group to accomplishing the given tasks.

\subsection{Instruments}

The DCT is applied by diverse studies in pragmatics literature to categorize the semantic formulas of different speech acts (Sasaki, 1998; Beebe and Cumming, 1996; Kasper and Dahl, 1991). Nguyen's (2005) DCT is adopted to elicit the criticism expressions by peer-feedback in this study (refer to Appendix B). The task of peer-feedback is commonly used in the academic setting among classmates who provide comments on each other's essays. Hence, all the participants are asked to write an argumentative essay of about 200-word in English. The topic is about 'the pros and cons of public transportation as opposed to private transportation'. This topic is not hard to understand because all learners have knowledge about it. Besides, it is taken from the commercially IELTS practice book. After that, the participants have been asked to check the writing of each other and to provide comments where necessary. Then, the DCT is conducted and it comprises an introduction and the task. The former illustrates the aim of DCT to confirm 
that all the participants have no difficulty in understanding the task. As for the task, it involves four situations on topics of criticism: 'essay organization', 'quality of argumentation', 'task fulfillment', and 'cohesion'. The researcher has explained these topics before conducting the DCT. The social variables have been already controlled with regard to power (equal), distance (neutral), and imposition degree. All the given situations occur among classmates who are asked to provide feedback on each other's essays; this is necessary to make sure that the data are more comparable.

After applying the DCT, a focus group interview (FGI) is conducted on another day to support the data analysis and to provide better explanation. This type of interview is commonly conducted on qualitative research by interviewing 4 or 6 participants (Creswell, 2012, p. 218). Thus, 10 participants from each group are selected to participate in the FGI. It includes guidelines that illustrate the aim of the current study and if there is any difficulty in understanding the interview. It also involves questions associated with the learners' expressions on the situations of DCT. However, both instruments (DCT and FGI) are piloted to 5 different MA learners from each group to make sure of the validity and reliability.

\subsection{Data Analysis}

Nguyen's (2005, p: 115-116) taxonomy of criticism supportive moves is adapted to code the data of this study (refer to Appendix C). Hence, the criticism expressions are analysed qualitatively with regard to the supportive moves. These devices are external mitigators occurring before and/or after the head act of criticism to ameliorate and soften the face damaging of it. These involve: 'steers', 'sweeteners', 'disarmers', 'grounders', and 'appreciations'. The last device of supportive moves 'appreciations' is a new category which is revealed in the data of this study. 
To analyse the data quantitatively, Chi-square test is utilised to decide whether there are any statistically significant differences in the use of supportive moves between the two groups and their genders. In addition, the data of the FGI are analysed qualitatively. For ensuring the reliability of data analysis, the data are coded by two inter-raters specialists in coding the speech acts and the result is $81 \%$.

\section{Results and Discussion}

\subsection{Supportive Moves of Criticism by Iraqi and Malay Learners}

On the whole, Figure 1 illustrates that there is a statistically significant difference $\left(\chi^{2} 23.023, p=<0.001\right)$ between Iraqis and Malays in producing the supportive moves of criticism across situations. Iraqi learners use more supportive moves than Malay learners in their criticisms $(52.54 \%$ vs. $47.46 \%$ ). Based on these results, Iraqi learners have tendency to increase the use of these devices to reduce the face damaging of their criticisms.

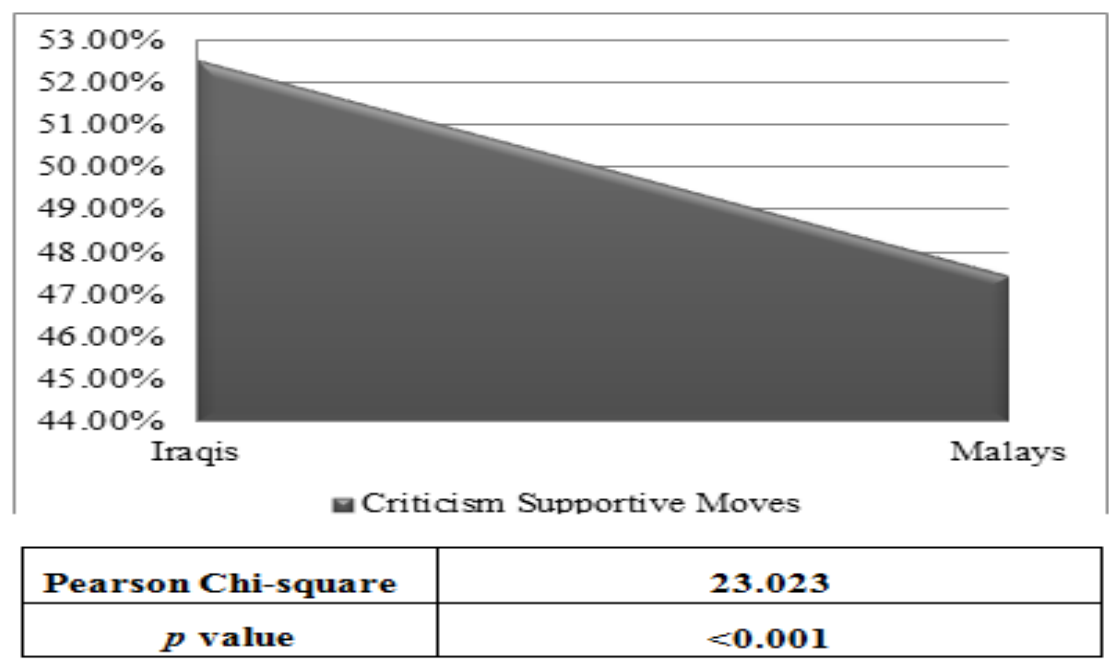

Figure 1: Percentages and Chi-square Value of Supportive Moves of Criticism across Situations 
As reported in Table 1 , there are statistically significant differences $\left(\chi^{2}\right.$ 18.491, $\left.p=<0.001, \chi^{2} 17.839, p=<0.001\right)$ between Iraqi and Malay learners in the use of direct and indirect criticisms. Iraqis use more direct criticisms than Malays (66.67\% vs. $35.17 \%$ ) who tend to use more indirect criticisms than Iraqis $(64.83 \%$ vs. $33.33 \%)$.

Table 1: Percentages and Chi-square Values of (In)direct Criticisms by Iraqis \& Malays

\begin{tabular}{ccccc}
\hline \hline Type of Strategy & Iraqis & Malays & $\begin{array}{c}\text { Pearson Chi- } \\
\text { square }\end{array}$ & $\begin{array}{c}\boldsymbol{p} \\
\text { value }\end{array}$ \\
\hline Direct Criticisms & $66.23 \%$ & $33.77 \%$ & $\mathbf{1 8 . 4 9 1}$ & $<\mathbf{0 . 0 0 1}$ \\
Indirect Criticisms & $34.72 \%$ & $65.28 \%$ & $\mathbf{1 7 . 8 3 9}$ & $<\mathbf{0 . 0 0 1}$ \\
\hline \hline
\end{tabular}

Accordingly, Figure 2 shows that there is a statistically significant difference $\left(\chi^{2} 17.839, p=0.001\right)$ in the production of supportive moves. Iraqis use more devices in their direct than their indirect criticisms across situations $(65.70 \%$ vs. $34.30 \%)$. Yet, there is no statistically significant difference in using the supportive moves by Malays between their direct and indirect criticisms across situations ( $51.87 \%$ vs. $48.13 \%)$. 


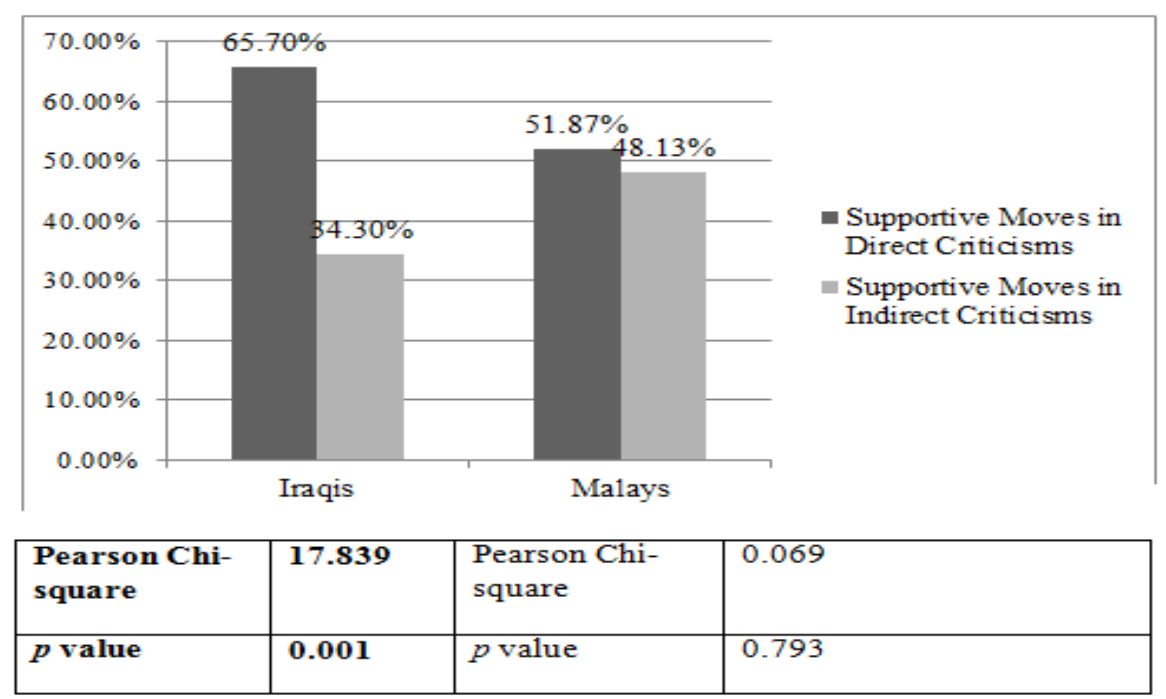

Figure 2: Percentages and Chi-square Values of Supportive Moves in Direct \& Indirect Criticisms across Situations

Iraqis' tendency for direct criticisms illustrates their overuse of supportive moves. These learners significantly overuse these devices in their direct than their indirect criticisms to reduce the face damaging of their direct criticisms. This is also stated in the FGI when these learners have emphasized that they modify their direct expressions by external softeners such as 'steers', 'sweeteners', 'disarmers', 'grounders', and 'appreciations'. Malay learners soften their direct and indirect criticisms by these devices, but there is no remarkable difference between these criticisms. These learners do not use these mitigators as much as Iraqi learners do in their direct criticisms. Moreover, Iraqis' increase of their supportive moves might be due to the issue that these learners tend to emphasize their linguistic competence by producing lengthy utterances and making their pragmatic meanings as clear as possible. This is in line with Ali (2016) who reveals that Iraqi EFL learners tend to use more supportive moves in their academic requests by email. 
Furthermore, Figure 3 reports that there are statistically significant differences in the use of 'grounders' $\left(\chi^{2} 12.233, p=<0.001\right)$, 'steers' $\left(\chi^{2}\right.$ 8.137, $\mathrm{p}=0.004)$, and 'sweeteners' $\left(\chi^{2}\right.$ 9.802, $\left.\mathrm{p}=0.002\right)$ between the two groups under study. Malays use more 'grounders' than Iraqis $(54.01 \%$ vs. $40.58 \%$ ) who tend to use more 'steers' and 'sweeteners' than Malays (Steers: $24.64 \%$ vs. $19.25 \%$; Sweeteners: $17.87 \%$ vs. $11.23 \%$ ). As for 'disarmers' and 'appreciations', there are no statistically significant differences in the use of them between Iraqis and Malays across situations (Disarmers $7.25 \%$ vs. 5.35\%; Appreciations $9.66 \%$ vs. $10.16 \%$ ).

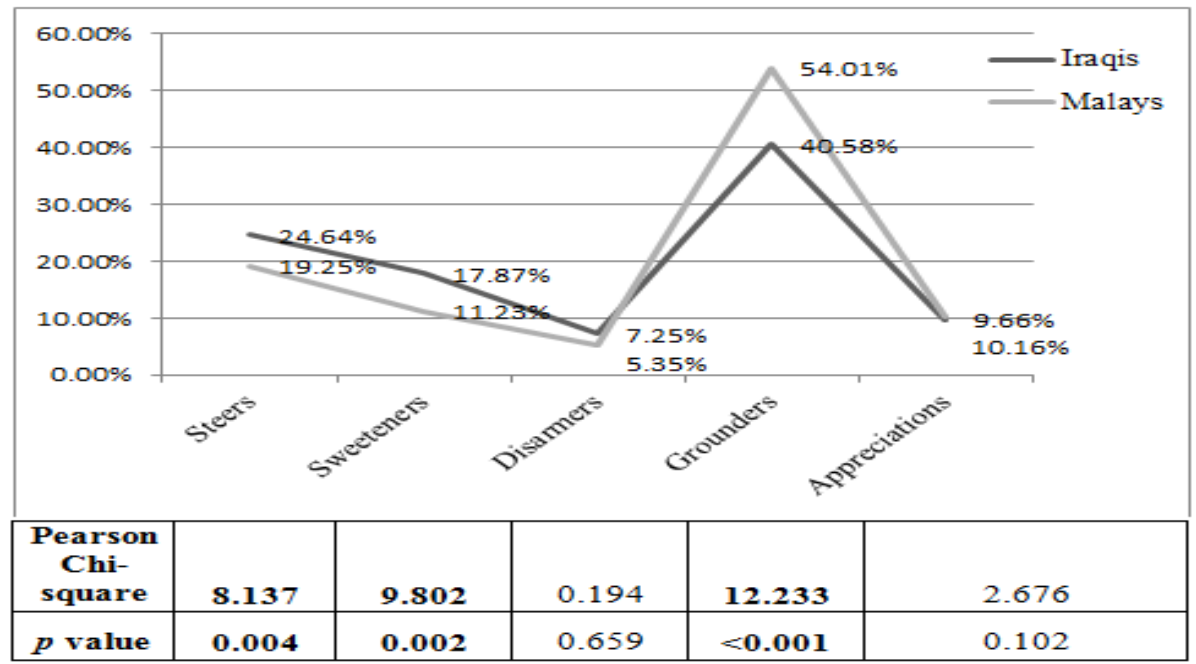

Figure 3: Percentages and Chi-square Values of Categories of Supportive Moves across Situations

In fact, the aforementioned mitigators are available in the IraqiArabic and Malay languages. As indicated in the FGI, both learners follow their first language norms and transfer these devices from their native language to their second language. However, there is a marked variation in the occurrence of these mitigators by both groups. As stated in the results and the FGI, Malay learners significantly use more 'grounders' than Iraqis in 
their criticisms. They produce more clarifications in their comments because of their nature to explain every point that would provide a good feedback on their classmates' essays. This is consistent with Farnia and Abdul Sattar (2014) who show that Malay university learners produce more 'grounders' than Iraqi university learners in their requests related to situations they know each other in. On the other hand, Iraqi learners considerably resort to 'steers' and 'sweeteners' more than Malay learners because they want to lead their classmates to the comment they like to highlight and to provide compliments to compensate for the aggressive act of their criticisms.

A word worth mentioning is that the 'grounders' device is the dominant mitigator among other external mitigators by Iraqis and Malays across situations. This is congruent with Farnia and Abdul Sattar (2014) who uncover that the 'grounder' is the most frequent device among other external devices used by Iraqi and Malay ESL learners in situations relevant to classmates' requests. That is due to the issue that a 'grounder' is a cooperative strategy used to support harmony in exchanges. It might be considered a way that the speaker tries his/her best to accomplish a smooth communication with a hope that his/her explanation or reason would have an influence on his/her hearer to understand the situation and be more cooperative. Both learners use simple clauses in the structure of their 'grounders' which do not require native-like expressions. Besides, clear reasons and justifications are produced by them to convey an explicit propositional aim in their comments. In doing so, the learner could be convinced of his/her classmate's criticism. Moreover, the excessive use of 'grounders' might be due to the learners' native language knowledge or to the global base of their pragmatic competence which are provided to all communicators. However, that device is considered a main component in 
most of speech acts because it is easily learned by learners in their academic study.

Furthermore, Table 2 states that the criticism supportive moves are commonly used by Iraqis in situations 1 (38.65\%), 2 (29.95\%), 4 (25.60\%), and $3(5.8 \%)$ respectively. As for Malays, their use of these devices from the most to the least common is in situations $2(32.62 \%), 1(31.55 \%), 4$ $(30.48 \%)$, and $3(5.35 \%)$ respectively. Iraqis prefer to use more 'grounders' while Malays highly resort to 'grounders' and 'steers' in most situations.

Table 2: Raw Frequency \& Percentage of Criticism Supportive Moves in each Situation

\begin{tabular}{|l|l|l|l|l|l|l|}
\hline Iraqis & Steers & Sweeteners & Disarmers & Grounders & $\begin{array}{l}\text { Appreciatio } \\
\text { ns }\end{array}$ & Total \\
\hline Situation 1 & $24(30.0 \%)$ & $12(15.0 \%)$ & $9(11.25 \%)$ & $31(38.75 \%)$ & $4(5.0 \%)$ & $80(38.65 \%)$ \\
\hline Situation2 & $8(12.9 \%)$ & $9(14.52 \%)$ & $6(9.68 \%)$ & $28(45.16 \%)$ & $11(17.24 \%)$ & $62(29.95 \%)$ \\
\hline Situation3 & $2(16.66 \%)$ & $0(0.0 \%)$ & $0(0.0 \%)$ & $5(41.67 \%)$ & $5(41.67 \%)$ & $12(5.8 \%)$ \\
\hline Situation4 & $17(32.07 \%)$ & $16(30.19 \%)$ & $0(0.0 \%)$ & $20(37.74 \%)$ & $0(0.0 \%)$ & $53(25.6 \%)$ \\
\hline Malays & Steers & Sweeteners & Disarmers & Grounders & $\begin{array}{l}\text { Appreciatio } \\
\text { ns }\end{array}$ & Total \\
\hline Situation1 & $9(15.25 \%)$ & $6(10.17 \%)$ & $0(0.0 \%)$ & $37(62.71 \%)$ & $7(11.87 \%)$ & $59(31.55 \%)$ \\
\hline Situation2 & $13(21.31 \%)$ & $6(9.84 \%)$ & $5(8.19 \%)$ & $31(50.82 \%)$ & $6(9.84 \%)$ & $61(32.62 \%)$ \\
\hline Situation3 & $3(30.0 \%)$ & $3(30.0 \%)$ & $0(0.0 \%)$ & $4(40.0 \%)$ & $0(0.0 \%)$ & $10(5.35 \%)$ \\
\hline Situation4 & $11(19.3 \%)$ & $6(10.53 \%)$ & $5(8.77 \%)$ & $29(50.87 \%)$ & $6(10.53 \%)$ & $57(30.48 \%)$ \\
\hline
\end{tabular}

In situation 1, Iraqis mostly prefer to use 'grounders' (38.75\%), followed by 'steers' (30.0\%), 'sweeteners' (15.0\%), 'disarmers' (11.25\%), and 'appreciations' (5.0\%). Malays' use of supportive moves from the highest to the lowest occurrence comprises 'grounders' (62.71\%), 'steers' (15.25\%), 'appreciations' (11.87\%), and 'sweeteners' (5.0\%). They do not prefer to use 'disarmers' in situation 1. Both learners use supportive moves to underuse their criticisms on the essay organization. For example, 
Iraqis: - Thankyou for your efforts, but please it is not a good way to organize the essay because there are no topic sentence and no conclusion. (Appreciation \& Grounder)

- I have some comments. Please your essay about transportation is not good because your introduction does not have conclusion. (Steer \& Grounder)

- Your topic is interesting but I think there is problem in your organization. (Sweetener)

Malays:- $I$ appreciate your effort, but it seems that your essay is not very well-organized.

(Appreciation)

- My comments: You have two conclusions in the organization of your essay! (Steer)

- I suggest that you organize your essay in a proper way because your introduction and body are not quite related. (Grounder)

In situation 2, Iraqis highly resort to 'grounders' (45.16\%) more than 'appreciations' (17.24\%), 'sweeteners' (14.52\%), 'steers' (12.9\%), and 'disarmers' (9.68\%). As for Malays, the 'grounders' (50.82\%) device is the most common followed by 'steers' (21.31\%), 'sweeteners' and 'appreciations' (which have a similar occurrence 9.84\%), and 'disarmers' $(8.19 \%)$. For example,

Iraqis:-Because you don't develop your argument correctly, I advise you to give more details and show your conclusion. (Grounder)

-My point is that I think there is difficulty in understanding your ideas. (Steer)

- ...please you must develop your argument well please by more examples about transportation. This is because you do not focus on your writing. (Disarmer)

Malays:- Please but this is not a well-illustrative argument. This is related to your way of thinking. (Disarmer)

-Would you add some more sentences to your argument? because you didn't clarify the ideas clearly. (Grounder)

-Here is my comment. I suggest that you support your argument using illustrative examples and evidence about transportation. (Steer)

- I have some points on your essay. The topic sentence needs more elaboration and argument. (Steer)

With regard to situation 3, the 'grounders' and 'appreciations' (41.67\% vs. $41.67 \%$ ) are the most frequent mitigators by Iraqis followed by 'steers' (16.66\%) while 'sweeteners' and 'disarmers' are quite avoided. Malays rely on 'grounders' (40.0\%) and 'steers' and 'sweeteners' (30.0\% vs. $30.0 \%$ ); yet, they avoid using 'disarmers' and 'appreciations'. For example, 
Iraqis: -It is not a correct way in fulfilling it please because your points are not relevant enough. (Grounder)

- I have some points. Please the problem is that your main statement is too narrow which makes you wander off your essay. (Steer)

Malays: - One issue is that please would you consider these points... (Steer)

-Your theme is motivating; but I would advise you to focus on the following points to achieve it properly. (Sweetener)

In situation 4, Iraqis mostly depend on 'grounders' (37.74\%) alongside 'steers' (32.07\%) and 'sweeteners' (30.19\%), but they avoid using 'disarmers' and 'appreciations'. As for Malays, the 'grounders' (50.87\%) device is the most frequent device followed by 'steers' (19.3\%), 'sweeteners' and 'appreciations' (10.53\% vs.10.53\%), and 'disarmers' (8.77\%). For example,

Iraqis: It is not a coherent way in your writing because I cannot find any linking words. (Grounder)

-This is my comment. The problem in your writing is that your ideas are not connected. (Steer)

-Nice topic, but you must pay attention to linking words and grammatical mistakes please. (Sweetener)

Malays: -I have some comments: It could have been better to use linking words in your essay.

(Steer)

-Thank you for being thoughtful, but would you connect your ideas using cohesive devices? (Appreciation)

- Please it is necessary to include cohesive devices in your essay because you do not develop a logical flow of ideas. (Grounder)

\subsection{Supportive Moves of Criticism by Gender}

Figure 3 illustrates that there are statistically significant differences between females and males of both learners $\left(\chi^{2} 19.841, p=0.001\right.$ vs. $\chi^{2} 16.413$, $p=0.002$ ). Iraqi and Malay females significantly use more supportive moves than Iraqi and Malay males in their criticisms (Iraqis: $57.97 \%$ vs. $42.03 \%$; Malays: $52.41 \%$ vs. $47.59 \%)$. 


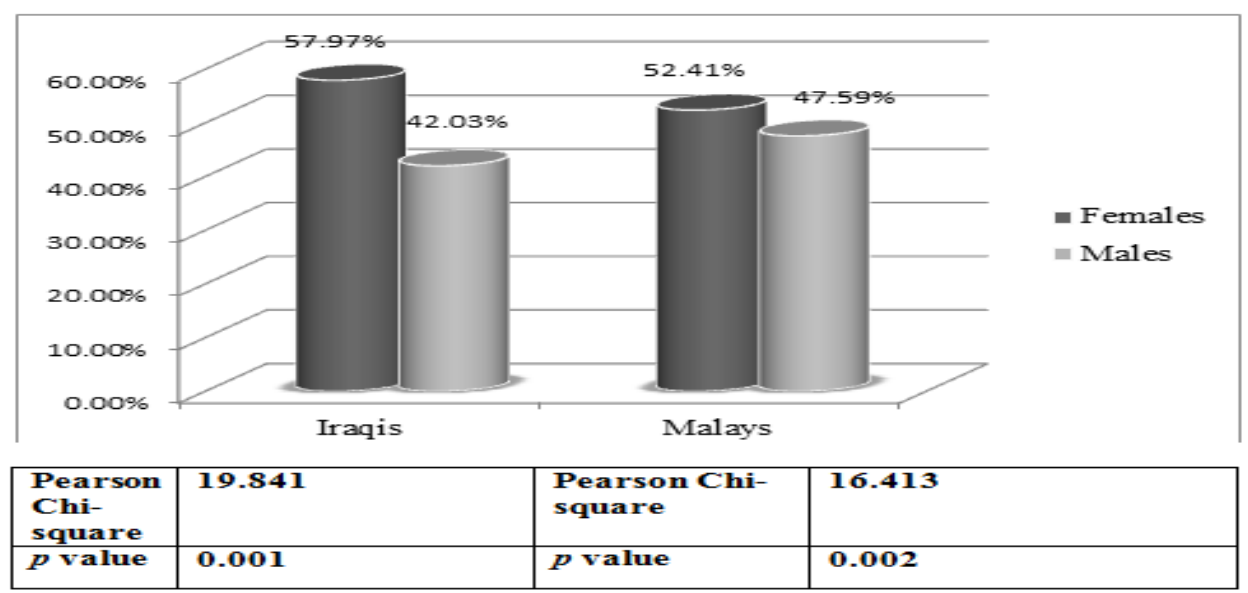

Figure 3: Percentages and Chi-square Values of Criticism Supportive Moves by Gender

Based on the results and the FGI, Iraqi and Malay females produce more external mitigators to support the head acts of their criticisms. This is due to their nature of being emotional and cooperative with their classmates. The females have discussed that they do not like to embarrass their classmates or threaten their faces and thus they provide more external softeners in their criticisms. This is in line with Mills (2003) and Holmes (1995) who show that females tend to be more polite and cooperative than males in their strategies and mitigators in order not to threaten their addressee's face. Besides, Table 2 illustrates the supportive moves of criticism preferred by Iraqi and Malay genders and shows the (dis)similarities between females and males of each group in the use of them.

Table 2: Raw Frequency \& Percentage of Supportive Moves of Criticism by Gender 


\begin{tabular}{|c|c|c|}
\hline $\begin{array}{c}\text { Criticism Supportive } \\
\text { Moves by Iraqis }\end{array}$ & Females & Males \\
\hline Steers & $21(17.5 \%)$ & $30(34.48 \%)$ \\
\hline Sweeteners & $31(25.84 \%)$ & $6(6.9 \%)$ \\
\hline Disarmers & $11(9.16 \%)$ & $8(9.2 \%)$ \\
\hline Grounders & $48(40.00 \%)$ & $32(36.78 \%)$ \\
\hline Appreciations & $9(7.5 \%)$ & $11(12.64 \%)$ \\
\hline Total & $120(57.97 \%)$ & $87(42.03 \%)$ \\
\hline $\begin{array}{c}\text { Criticism Supportive } \\
\text { Moves by Malays }\end{array}$ & Females & $14(15.74 \%)$ \\
\hline Steers & $22(22.44 \%)$ & $9(10.11 \%)$ \\
\hline Sweeteners & $12(12.24 \%)$ & $6(6.74 \%)$ \\
\hline Disarmers & $4(4.1 \%)$ & $51(57.30 \%)$ \\
\hline Grounders & $50(51.02 \%)$ & $9(10.11 \%)$ \\
\hline Appreciations & $10(10.20 \%)$ & $89(47.59 \%)$ \\
\hline Total & $98(52.41 \%)$ & \\
\hline
\end{tabular}

The results uncover that Iraqi and Malay genders use similar categories of supportive moves to ameliorate their criticisms. That is, the females and males of both groups produce such devices as 'steers', 'sweeteners', 'disarmers', 'grounders', and 'appreciations'. In addition, the 'grounders' device is more frequently used than other devices by these genders to support their criticisms by reasons and details (Iraqis: $40.00 \%$ vs. 36.78\%; Malays: $51.02 \%$ vs. $57.30 \%)$.

Yet, noticeable differences in the occurrence of the external devices are observed between the females and males of both groups. While Iraqi females prefer to use 'grounders', 'sweeteners', 'steers', 'disarmers', and 'appreciations' respectively, Iraqi males show preference for 'grounders', 'steers', 'appreciations', 'disarmers', and 'sweeteners' respectively. Iraqi females prefer to use more 'grounders' and 'sweeteners' than Iraqi males who tend to use more 'steers' and 'appreciations' in their criticisms. As demonstrated in the FGI, that is due to the Iraqi females' nature in achieving their aims by providing more verbose utterances via reasons, clarifications, and expressions of compliments. In doing so, they mitigate the impact of 
their criticisms and support the social interaction with their classmates. Iraqi males tend to guide their classmates to the comments they highlight and they provide expressions of appreciation that support their criticisms.

With reference to Malays, the females have tendency to use 'grounders', 'steers', 'sweeteners', 'appreciations', and 'disarmers' respectively. Malay males rely on 'grounders', 'steers', 'sweeteners and appreciations', and 'disarmers' respectively. They prefer to use more explanations and reasons than the females. Besides, there is no considerable difference in the use of 'appreciations' between the females and males. Malay females also tend to use more 'steers' and 'sweeteners' than Malay males to help direct their classmates to the given feedback and stress closeness by compliment expressions.

However, both genders of both groups use 'disarmers' sparingly because they prefer to use other external devices in their criticisms. These learners might be aware of the damaging act that their criticisms might cause to their classmates in their utterances of 'disarmers'.

\section{Conclusion}

The current study investigates the supportive moves of criticism used by Iraqi and Malay ESL learners and shows the similarities and differences between females and males of each group in the use of these mitigators. The criticism is a face threatening act that could be produced properly using supportive moves to reduce its impact on the addressee. Both groups use similar devices of supportive moves to mitigate their criticisms, but they differ in the frequency of occurrence of these mitigators. Iraqi learners use more supportive moves than Malay learners due to their higher preference for direct criticisms than Malays. Thus, Iraqis produce more supportive 
moves in their direct than their indirect criticisms to reduce the face damaging of directness. Malay learners tend to moderately use supportive moves in their direct and indirect criticisms.

Besides, both groups follow their first language norms by transferring the criticisms supportive moves from their native language into their second language. The 'grounders' device is the most frequent external mitigator by both groups whereby reasons and explanations are provided in their criticisms. But, Malays significantly use more 'grounders' than Iraqis who prefer to use more 'steers' and 'sweeteners' than Malays. Both genders of both groups use identical categories of supportive moves in their criticisms. Yet, Iraqi and Malay females produce more supportive moves than Iraqi and Malay males due to their nature of being passionate and cooperative. They consider their classmates' feelings by reducing the embarrassment that their criticisms could cause and showing more cooperation and closeness.

Hence, this study shows the value of performing the supportive moves of criticism by ESL learners across two different cultures. This would raise the learners' awareness of the cultural (dis)similarities in producing criticisms. ESL and/or EFL teachers should consider that when designing programs to strengthen the learners' pragmatic consciousness in the use of the linguistic aspects and their relation to the social values of each culture. The findings inform the curriculum designers about the speech act of criticism and how it is reduced by the external mitigators in an ESL context so that miscommunication can be avoided between exchanges by learners. It also displays the similarities and differences between genders of ESL learners in the use of supportive moves of criticism. All of this would add to the materials designed by teachers of English and would contribute to the development of ESL and/or EFL learners' pragmatic knowledge. 


\section{References}

1. Abdullah, S. S. (2013), Pragmatic transfer in the speech acts of criticizing and respondingby EFL speakers of colloquial Egyptian Arabic. Retrieved February 27, 2018, from http://search.mandumah.com/Record/678905.

2. Ali, Sh. A. (2016). An interlanguage pragmatics study of Iraqi EFL learners' use of request in student-faculty e-mail communication. (Unpublished doctoral dissertation). Penang, Malaysia: Universiti Sains Malaysia.

3. Al Kayed, M. and Al-Ghoweri, H. (2019). A socio-pragmatic study of speech act of criticism in Jordanian Arabic. European Journal of Scientific Research, (1), 105-117

4. Austin, J. (1962). How to do things with words. Oxford: Oxford University Press.

5. Beebe, L. M. \& Cummings, M. C. (1996). Natural speech act data versus written questionnaire data: How data collection method affects speech act performance. In S. M. Gass \& J. Neu (Eds.). Speech acts across cultures (pp. 65-86). Berlin: Mouton de Gruyter.

6. Bella, S. (2011). Mitigation and politeness in Greek invitation refusals: Effects of length of residence in the target community and intensity of interaction on non-native speakers' performance. Journal of Pragmatics, 43(6), 1718-1740.

7. Blum-Kulka, S., House, J., \& Kasper, G. (Eds.). (1989). Crosscultural pragmatics: Requests and apologies. Norwood, NJ: Ablex.

8. Brown, P., \& Levinson, S. C. (1987). Politeness: Some universals in language usage. Cambridge: Cambridge University Press.

9. Caffi, C. (1999). On mitigation. Journal of Pragmatics, 31, 881-909.

10. Creswell, J. W. (2012). Educational research: Planning, conducting, and evaluating quantitative and qualitative research ( $4^{\text {th }}$ Edition). New York: Pearson Education.

11. Darweesh, A. D. (2011). Speech act of criticizing in MSA Arabic. Retrieved February 28, 2018

12. from http:// search.mandumah.com/Record/681234.

13. Farnia, M. and Abdul Sattar, H. Q. (2015). A sociopragmatic analysis of the speech act of criticism by Persian native speakers. International Journal of Humanities and Cultural Studies, 2(3), 305327.

14. Farnia, M. and Abdul Sattar, H. Q. (2014). A cross-cultural study of request speech act: Iraqi and Malay students. Applied Research on English Language, 3(2), 35-54. 
15. Fraser, B. (1990). Perspectives on politeness. Journal of Pragmatics, 14(2), 219-236.

16. Holmes, J. (1995). Women, men and politeness. New York: Longman.

17. Kasper, G. \& Dahl, M. (1991). Research methods in interlanguage pragmatics. Studies in second language acquisition, 13, 215-247.

18. Kecskes, I. (2017). Cross-cultural and intercultural pragmatics. In Y. Huang (Ed.), The Oxford Handbook of Pragmatics (PP: 400-415). Oxford: Oxford University Press.

19. Leech, G. (1983). Principles of pragmatics. London: Longman.

20. Mills, S. (2003). Gender and politeness. Cambridge: Cambridge University Press.

21. Min, S. C. (2008). Study on the differences of speech act of criticism in Chinese and English. US-China Foreign Language, 6(3), 74-77.

22. Nguyen, M. T. (2005). Criticizing and responding to criticism in a foreign language: A study of Vietnamese learners of English (doctoral dissertation). Auckland: University of Auckland.

23. Nguyen, M. (2008). Criticizing in an L2: Pragmatic strategies used by Vietnamese EFL learners. Intercultural Pragmatics, 1(5), 41-66.

24. Roever, C. (2006). Validation of a web-based test of ESL pragmalinguistics. Language Testing, 23(2), 229-256.

25. Sasaki, M. (1998). Investigation EFL student's production of speech acts: A comparison of production questionnaire and role-plays. Journal of Pragmatics, 30, 457-484.

26. Searle, J. (1979). Expression and meaning: Studies in the theory of speech acts. New York: Cambridge University Press.

27. Thomas, J. (1983). Cross-cultural pragmatic failure. Applied Linguistics, 4(2), 91-112.

28. Wierzbicka, A. (1987). English speech act verbs. A semantic dictionary. Marrickville: Academic Press Australia.

\section{About the author:}

Dr. Shurooq Abboodi Ali is an assistant professor at College of Arts, University of Baghdad. She got $\mathrm{PhD}$ in Applied Linguistics from Universiti Sains Malaysia, Malaysia. She has a number of published papers nationally and internationally. Her research interests are in the areas of pragmatics and discourse analysis.

Email:shurooq_eng@yahoo.com 


\title{
الجنس والوسائل الداعمة للنقا: أدلة من مجتمعات متكلمة للهجة العربية_العراقية واللغة الماليزية منية
}

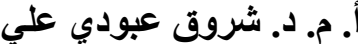

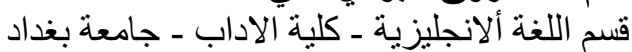

خلاصة البحث

تهدف الدر اسة الى كثف التشابهات والاختلافات بين متعلمين جامعيين عر اقيين وماليزيين مع الدان

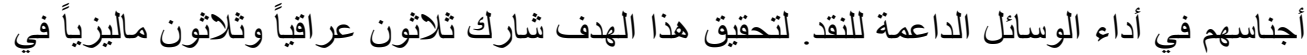

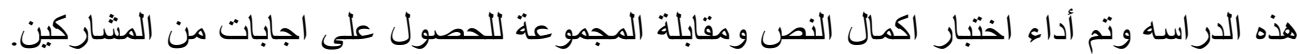

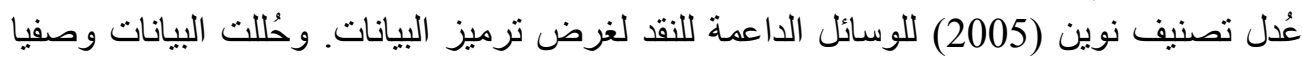

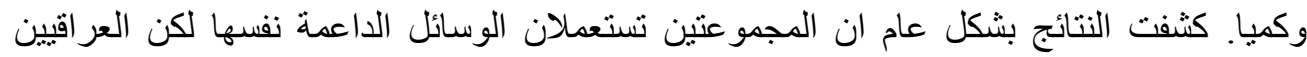
يأدون وسائل اكثر من الماليزيين في نقدهم. على الرغم من أنّ كلا الاناث و الذكور لكان لكلا المجمو عتين

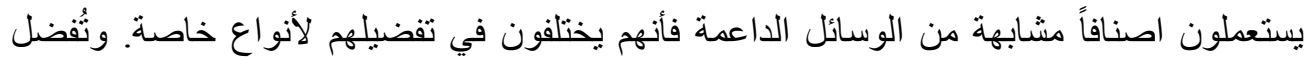

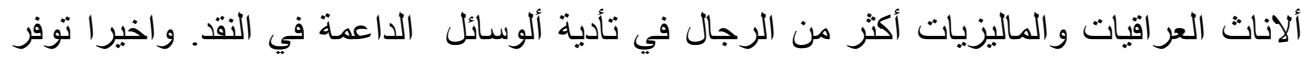

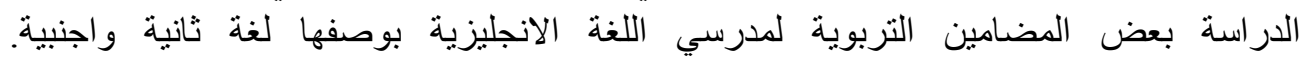

الكلمات المفتاحية: النقد, الوسائل الداعمة, الجنس, عر اقيون, ماليزيون

\section{Appendix A: Description of the Participants}

\begin{tabular}{|c|c|c|}
\hline & Iraqis & Malays \\
\hline Gender & 15 males, 15 females & 15 males, 15 females \\
\hline Age & $25-35$ & $25-35$ \\
\hline 1 am currently enrolled in: & MA & MA \\
\hline Area of study & $\begin{array}{c}\text { Engineering, Physics, } \\
\text { Computer, Pharmacy, and } \\
\text { management }\end{array}$ & $\begin{array}{c}\text { Engineering, Physics, } \\
\text { Computer, Pharmacy, and } \\
\text { management }\end{array}$ \\
\hline $\begin{array}{c}\text { How long have you been in } \\
\text { Malaysia? (Iraqis only) }\end{array}$ & Iraqi-Arabic & Bahasa Malay \\
\hline
\end{tabular}




\section{Appendix B: Description of DCT}

\begin{tabular}{|c|l|}
\hline $\begin{array}{c}\text { No. of } \\
\text { Situations }\end{array}$ & $\begin{array}{l}\text { In reference to an essay your friend has written, what would you say in the } \\
\text { following hypothetical situations: }\end{array}$ \\
\hline $\mathbf{1}$ & $\begin{array}{l}\text { What would you say to your friend if you think her/his essay was not very well- } \\
\text { organized, so it was rather difficult to follow her/his ideas? }\end{array}$ \\
\hline $\mathbf{2}$ & $\begin{array}{l}\text { What would you say to your friend if you think in some instances she or he didn't } \\
\text { support her/his arguments with relevant examples and evidence, so these } \\
\text { arguments were hard to convince readers? }\end{array}$ \\
\hline $\mathbf{3}$ & $\begin{array}{l}\text { What would you say to your friend if you think she or he sometimes wandered off } \\
\text { the topic? }\end{array}$ \\
\hline $\mathbf{4}$ & $\begin{array}{l}\text { What would you say to your friend if you think she or he didn't often make use of } \\
\text { linking words, so the essay seemed to lack cohesion? }\end{array}$ \\
\hline
\end{tabular}

\section{Appendix C: Nguyen's (2005, p: 115-116) Taxonomy of Supportive}

\section{Moves of Criticism}

\begin{tabular}{|c|c|c|}
\hline Type & Characteristics & Example \\
\hline a. Steers & $\begin{array}{l}\text { Utterances that } \mathrm{S} \text { used to lead } \mathrm{H} \\
\text { onto the issue he or she was going } \\
\text { to raise. }\end{array}$ & $\begin{array}{l}\text { "I read your essay and here are } \\
\text { some my own ideas of this" (L), } \\
\text { "Ah I have some comments } \\
\text { about your writing" (L). }\end{array}$ \\
\hline b. Sweeteners & $\begin{array}{l}\text { Compliments or positive remarks } \\
\text { paid to } H \text { either before or after a } \\
\text { criticism to compensate for the } \\
\text { offensive act. (It is acknowledged } \\
\text { that an alternative term to } \\
\text { "sweeteners" is "positive remarks". }\end{array}$ & $\begin{array}{l}\text { "There are quite good relevant } \\
\text { ideas that you presented (.) ah but } \\
\text { " (NE). }\end{array}$ \\
\hline c. Disarmers & $\begin{array}{l}\text { Utterances that } S \text { used to show his } \\
\text { or her awareness of the potential } \\
\text { offence that his or her speech might } \\
\text { cause } H \text {. }\end{array}$ & $\begin{array}{l}\text { "You had a few spelling mistakes } \\
\text { (.) but I think that's because you're } \\
\text { writing too quickly, (.) } \\
\text { nothing too major." (NE) }\end{array}$ \\
\hline d. Grounders & $\begin{array}{l}\text { The reasons given by } \mathrm{S} \text { to justify } \\
\text { his or her intent. }\end{array}$ & $\begin{array}{l}\text { "I think "is" is better than "are" } \\
\text { there because traffic (.2) ah } \\
\text { single?" (NE). }\end{array}$ \\
\hline e. Appreciationd & $\begin{array}{l}\text { Appreciative expressions used to } \\
\text { estimate the addressee's task. }\end{array}$ & $\begin{array}{l}\text { I appreciate your effort, but it } \\
\text { seems that your essay is not very } \\
\text { well-organized. } \\
\text { Thank you for your efforts, but } \\
\text { please it is not a good way to } \\
\text { organize the essay... }\end{array}$ \\
\hline
\end{tabular}

